\title{
Correction to: Ulnar nerve entrapment in Guyon's canal caused by a ganglion cyst: two case reports and review of the literature
}

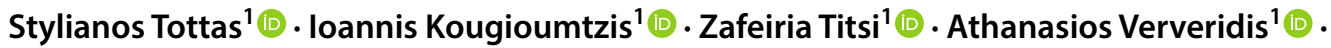 \\ Konstantinos Tilkeridis ${ }^{1}$ (D) . Georgios I. Drosos ${ }^{1}$ (i)
}

Published online: 27 June 2019

○) Springer-Verlag France SAS, part of Springer Nature 2019

\section{Correction to: \\ European Journal of Orthopaedic Surgery \& Traumatology \\ https://doi.org/10.1007/s00590-019-02461-z}

The original version of this article unfortunately contained a mistake. Table 1 footnotes were missing.

The corrected Table 1 with footnotes is given in the next page.

The original article has been corrected.

The original article can be found online at https://doi.org/10.1007/ s00590-019-02461-z.

Stylianos Tottas

stottasdoc@hotmail.com

1 Orthopaedic Department, Medical School, University General Hospital of Alexandroupolis, Democritus University of Thrace, St. Niarhos 1, Dragana, 68100 Alexandroupolis, Greece 
Table 1 Cases of ulnar neuropathy in Guyon's canal, caused by a ganglion, reported in the literature

\begin{tabular}{|c|c|c|c|c|c|c|c|c|c|}
\hline References & Cases & Zone $^{\mathrm{a}}$ & Age & Sex & $\begin{array}{l}\text { Symp- } \\
\text { toms }\end{array}$ & DSBS & Side & $\begin{array}{l}\text { Treat- } \\
\text { ment }\end{array}$ & Follow-up ${ }^{b}$ \\
\hline $\begin{array}{l}\text { 1. Brooks } \\
{[18]}\end{array}$ & 3 & $\begin{array}{l}1 \text { all } 3 \\
\text { cases }\end{array}$ & Mean 41 & $\begin{array}{l}2 \text { Female } / 1 \\
\text { male }\end{array}$ & $\begin{array}{c}\mathrm{w}, \mathrm{par}, \\
\mathrm{p}, \mathrm{a}\end{array}$ & 6-7 months & $\begin{array}{c}2 \mathrm{right} / 1 \\
\text { left }\end{array}$ & $\begin{array}{l}\text { Surgical } \\
\text { exci- } \\
\text { sion }\end{array}$ & 4 months -8 year \\
\hline $\begin{array}{l}\text { 2. Seddon } \\
{[19]}\end{array}$ & 4 & 2 all cases & Mean 45 & $\begin{array}{l}3 \text { Male/1 } \\
\text { female }\end{array}$ & $\begin{array}{l}\mathrm{w}, \mathrm{par} \\
\mathrm{p}, \mathrm{n}\end{array}$ & 12 months & $\begin{array}{c}1 \mathrm{right} / 3 \\
\text { left }\end{array}$ & $\begin{array}{l}\text { Surgical } \\
\text { exci- } \\
\text { sion }\end{array}$ & 7 months -16 months \\
\hline $\begin{array}{l}\text { 3. Jenkins } \\
{[20]}\end{array}$ & 1 & 2 & 51 & Female & $\mathrm{w}$, par, $\mathrm{p}$ & 2 months & - & $\begin{array}{l}\text { Surgical } \\
\text { exci- } \\
\text { sion }\end{array}$ & 6 months \\
\hline $\begin{array}{l}\text { 4. Richmond } \\
\text { [21] }\end{array}$ & 12 & $\begin{array}{l}1 \text { nine } \\
\text { cases/2 } \\
\text { three } \\
\text { cases }\end{array}$ & Mean 47 & $\begin{array}{l}2 \text { Male/10 } \\
\text { female }\end{array}$ & $\begin{array}{l}\mathrm{w}, \mathrm{p}, \mathrm{par} \\
\mathrm{n}, \mathrm{a}\end{array}$ & 4 months & - & $\begin{array}{l}\text { Surgical } \\
\text { exci- } \\
\text { sion }\end{array}$ & $\begin{array}{l}3 \text { months }-12 \text { months } / 1 \\
\text { case slight weakness } \\
10 \text { years later }\end{array}$ \\
\hline $\begin{array}{l}\text { 5. Vander- } \\
\text { pool et al. } \\
{[22]}\end{array}$ & 13 & $\begin{array}{l}1 \text { eight } \\
\text { cases/2 } \\
\text { five } \\
\text { cases }\end{array}$ & $\begin{array}{l}43,54, \\
\text { (two } \\
\text { illustra- } \\
\text { tive } \\
\text { cases) }\end{array}$ & $\begin{array}{l}1 \text { male/1 } \\
\text { female } \\
\text { (two } \\
\text { illustra- } \\
\text { tive } \\
\text { cases) }\end{array}$ & $\mathrm{w}, \mathrm{p}, \mathrm{par}$ & $\begin{array}{l}\text { 1-4 months (two } \\
\text { illustrative cases) }\end{array}$ & $\begin{array}{l}1 \text { right/1 } \\
\text { left } \\
\text { (two } \\
\text { illustra- } \\
\text { tive } \\
\text { cases) }\end{array}$ & $\begin{array}{l}\text { Surgical } \\
\text { exci- } \\
\text { sion all } \\
\text { cases }\end{array}$ & Few months all cases \\
\hline $\begin{array}{l}\text { 6. Hayes } \\
\text { et al. [23] }\end{array}$ & 1 & 2 & 46 & Male & $\mathrm{w}$ & $1 / 2$ month & Left & $\begin{array}{l}\text { Surgical } \\
\text { exci- } \\
\text { sion }\end{array}$ & $\begin{array}{l}\text { Partial recov- } \\
\text { ery-4 months }\end{array}$ \\
\hline $\begin{array}{l}\text { 7. Forshell } \\
\text { and Hag- } \\
\text { strom [24] }\end{array}$ & $\begin{array}{l}2 \\
36 \text { total }\end{array}$ & $\begin{array}{l}2 / 2 \\
1-20 / 2- \\
16\end{array}$ & $66 / 65$ & Male/male & $\mathrm{p}, \mathrm{a}, \mathrm{w}$ & 25 years/1 year & Left/left & $\begin{array}{l}\text { Surgical } \\
\text { exci- } \\
\text { sion }\end{array}$ & Relieved by symptoms \\
\hline $\begin{array}{l}\text { 8. McDow- } \\
\text { ell and } \\
\text { Henceroth } \\
\text { [25] }\end{array}$ & 1 & $\begin{array}{l}2 \text { Mid- } \\
\text { palm }\end{array}$ & 34 & Male & $\mathrm{a}, \mathrm{w}$ & 8 months & Right & $\begin{array}{l}\text { Surgical } \\
\text { exci- } \\
\text { sion }\end{array}$ & $\begin{array}{l}14 \text { months } \\
\text { No reinnervation }\end{array}$ \\
\hline $\begin{array}{l}\text { 9. Bowers } \\
\text { and Dop- } \\
\text { pelt [13] }\end{array}$ & 1 & 2 & 50 & Male & $\mathrm{p}, \mathrm{w}, \mathrm{a}$ & 6 months & Right & $\begin{array}{l}\text { Surgical } \\
\text { exci- } \\
\text { sion }\end{array}$ & $\begin{array}{l}\text { Partly return of } \\
\text { strength (5) }\end{array}$ \\
\hline $\begin{array}{l}\text { 10. Kusch- } \\
\text { ner et al. } \\
{[26]}\end{array}$ & 2 & $2 / 2$ & $46 / 70$ & 2 Male & $\mathrm{p}, \mathrm{w}$ & $\begin{array}{l}9 \text { months/several } \\
\text { weeks }\end{array}$ & 2 left & $\begin{array}{l}\text { Surgical } \\
\text { exci- } \\
\text { sion }\end{array}$ & $\begin{array}{l}4 \text { months/several } \\
\text { months }\end{array}$ \\
\hline $\begin{array}{l}\text { 11. Feldman } \\
\text { et al. [27] }\end{array}$ & 1 & $\begin{array}{l}\text { 2/Mid- } \\
\text { palm }\end{array}$ & 45 & Female & & 4 months & Right & $\begin{array}{l}\text { Surgical } \\
\text { exci- } \\
\text { sion }\end{array}$ & - \\
\hline $\begin{array}{l}\text { 12. Shu } \\
\text { et al. [28] }\end{array}$ & 1 & 1 & 61 & Female & $\mathrm{w}, \mathrm{a}$ & 3 months & Right & $\begin{array}{l}\text { Surgical } \\
\text { exci- } \\
\text { sion }\end{array}$ & $\begin{array}{l}\text { Symptoms resolved } \\
\text { (24) }\end{array}$ \\
\hline $\begin{array}{l}\text { 13. Kita- } \\
\text { mura et al. } \\
{[29]}\end{array}$ & 1 & 3 & 44 & Female & $\mathrm{n}, \mathrm{p}$ & Few months & Right & $\begin{array}{l}\text { Surgical } \\
\text { exci- } \\
\text { sion }\end{array}$ & - \\
\hline $\begin{array}{l}\text { 14. Elias } \\
\text { et al. [30] }\end{array}$ & 1 & 2 & 48 & Male & par, p, w & 2 months & Right & $\begin{array}{l}\text { Surgical } \\
\text { exci- } \\
\text { sion }\end{array}$ & Symptoms resolved (1) \\
\hline $\begin{array}{l}\text { 15. Kob- } \\
\text { ayashi } \\
\text { et al. [10] }\end{array}$ & 1 & $\begin{array}{l}\text { 2/Mid- } \\
\text { palm } \\
\text { third } \\
\text { carpo- } \\
\text { meta- } \\
\text { carpal } \\
\text { joint) }\end{array}$ & 71 & Female & $\mathrm{w}, \mathrm{n}, \mathrm{p}, \mathrm{a}$ & 2 months & Left & $\begin{array}{l}\text { Surgical } \\
\text { exci- } \\
\text { sion }\end{array}$ & $21 / 2$ months \\
\hline $\begin{array}{l}\text { 16. Zielinski } \\
\text { [14] }\end{array}$ & 1 & 1 & 54 & Male & $\mathrm{w}, \mathrm{p}, \mathrm{n}, \mathrm{a}$ & 24 months & Right & $\begin{array}{l}\text { Surgical } \\
\text { exci- } \\
\text { sion }\end{array}$ & 3 months \\
\hline
\end{tabular}


Table 1 (continued)

\begin{tabular}{|c|c|c|c|c|c|c|c|c|c|}
\hline References & Cases & Zone $^{\mathrm{a}}$ & Age & Sex & $\begin{array}{l}\text { Symp- } \\
\text { toms }\end{array}$ & DSBS & Side & $\begin{array}{l}\text { Treat- } \\
\text { ment }\end{array}$ & Follow-up ${ }^{b}$ \\
\hline $\begin{array}{l}\text { 17. Nakam- } \\
\text { ichi and } \\
\text { Tachibana } \\
\text { [31] }\end{array}$ & $\begin{array}{l}1 \text { Total } \\
11\end{array}$ & 1 & 40 & $\begin{array}{c}\text { Female } \\
\text { (preg- } \\
\text { nant) }\end{array}$ & $\mathrm{w}, \mathrm{n}, \mathrm{a}$ & 6 months & Left & $\begin{array}{l}\text { Aspira- } \\
\text { tion and } \\
\text { splint- } \\
\text { ing }\end{array}$ & 12 months \\
\hline $\begin{array}{l}\text { 18. Papa- } \\
\text { thanasiou } \\
\text { et al. [32] }\end{array}$ & 1 & 2 & 27 & Male & $\mathrm{a}, \mathrm{w}$ & 7 days & Right & $\begin{array}{l}\text { Surgical } \\
\text { exci- } \\
\text { sion }\end{array}$ & $1 \frac{1 / 2}{2}$ \\
\hline $\begin{array}{l}\text { 19. Jacob } \\
\text { et al. [33] }\end{array}$ & 1 & $\begin{array}{l}\text { 2/Mid- } \\
\text { palm }\end{array}$ & 9 & Female & $\mathrm{w}$ & $\begin{array}{l}\text { Gradually progres- } \\
\text { sive }\end{array}$ & Right & - & - \\
\hline $\begin{array}{l}\text { 20. Duggal } \\
\text { et al. [34] }\end{array}$ & 1 & $\begin{array}{l}\text { 2/Mid- } \\
\text { palm } \\
\text { (3rd } \\
\text { carpo- } \\
\text { meta- } \\
\text { carpal } \\
\text { joint) }\end{array}$ & 20 & Male & $\mathrm{w}, \mathrm{a}$ & 2 months & Right & $\begin{array}{l}\text { Surgical } \\
\text { exci- } \\
\text { sion }\end{array}$ & $\begin{array}{l}\text { Normal motor strength } \\
\text { (24) }\end{array}$ \\
\hline $\begin{array}{l}\text { 21. Erkin } \\
\text { et al. [35] }\end{array}$ & 1 & 2 & 40 & Female & $\mathrm{P}$ & $1 / 2$ months & Left & $\begin{array}{l}\text { Surgical } \\
\text { exci- } \\
\text { sion }\end{array}$ & Significant recovery (7) \\
\hline $\begin{array}{l}\text { 22. Inapar- } \\
\text { thy et al. } \\
{[36]}\end{array}$ & 2 & $2 / 2$ & $59 / 72$ & male/male & $\mathrm{w}, \mathrm{a}$ & 6 months $/ 2$ months & Left/left & $\begin{array}{l}\text { Surgical } \\
\text { exci- } \\
\text { sion }\end{array}$ & $\begin{array}{l}\text { Total recovery }(4) / \\
\left(4^{1 / 2}\right)\end{array}$ \\
\hline $\begin{array}{l}\text { 23. Chan } \\
\text { et al. [37] }\end{array}$ & 1 & 2 & 54 & Female & $\mathrm{w}, \mathrm{a}$ & 6 months & Right & $\begin{array}{l}\text { Surgical } \\
\text { exci- } \\
\text { sion }\end{array}$ & Symptoms resolved (4) \\
\hline $\begin{array}{l}\text { 24. Chalidis } \\
\text { et al. [38] }\end{array}$ & 1 & 1 & 52 & Female & $\mathrm{p}, \mathrm{n}, \mathrm{a}$ & 4 months & Left & $\begin{array}{l}\text { Surgical } \\
\text { exci- } \\
\text { sion }\end{array}$ & $\begin{array}{l}\text { Symptoms totally } \\
\text { resolved (30) }\end{array}$ \\
\hline $\begin{array}{r}\text { 25. Pearce } \\
\text { et al. [9] }\end{array}$ & 1 & 1 & 29 & Female & $\mathrm{n}, \mathrm{w}$ & $1 / 2$ month & Right & $\begin{array}{l}\text { Surgical } \\
\text { exci- } \\
\text { sion }\end{array}$ & $\begin{array}{l}1 / 3 \text { slight dysesthesia/ } \\
\text { intact strength }\end{array}$ \\
\hline $\begin{array}{l}\text { 26. Almeida } \\
\text { and de } \\
\text { Carvalho } \\
\text { [39] }\end{array}$ & 1 & 2 & 49 & Male & $\mathrm{w}$ & $11 / 2$ month & Left & $\begin{array}{l}\text { Surgical } \\
\text { exci- } \\
\text { sion }\end{array}$ & 4 months full recovery \\
\hline $\begin{array}{l}\text { 27. Kwak } \\
\text { et al. [40] }\end{array}$ & 1 & 1 & 54 & Female & w, par & 1 month & Left & $\begin{array}{l}\text { Surgical } \\
\text { exci- } \\
\text { sion }\end{array}$ & Clinical recovery $(1 / 2)$ \\
\hline $\begin{array}{l}\text { 28. Okada } \\
\text { et al. [41] }\end{array}$ & 1 & 1 & 51 & Male & $\mathrm{n}$, par, a & - & Right & $\begin{array}{l}\text { Surgical } \\
\text { exci- } \\
\text { sion }\end{array}$ & $\begin{array}{l}\text { Symptoms resolved } \\
\text { (18) }\end{array}$ \\
\hline $\begin{array}{l}\text { 29. Chen } \\
\text { et al. [15] }\end{array}$ & $\begin{array}{l}1 \\
\text { Total } 13\end{array}$ & 1 & 43 & Male & $\mathrm{n}$ & 12 months & Right & $\begin{array}{l}\text { First } \\
\text { splint- } \\
\text { ing/ } \\
\text { surgical } \\
\text { exci- } \\
\text { sion }\end{array}$ & Symptoms resolved (4) \\
\hline $\begin{array}{l}\text { 30. Colbert } \\
\text { and Le } \\
{[42]}\end{array}$ & 1 & 2 & 69 & Male & $\mathrm{w}, \mathrm{p}$ & 14 months & Right & $\begin{array}{l}\text { Surgical } \\
\text { exci- } \\
\text { sion }\end{array}$ & $\begin{array}{l}10 \text { months total } \\
\text { recovery }\end{array}$ \\
\hline $\begin{array}{l}\text { 31. Wang } \\
\text { et al. [6] }\end{array}$ & 9 & $\begin{array}{l}2 \text { all } 9 \\
\text { cases }\end{array}$ & Mean 41 & $\begin{array}{l}5 \text { Male } \\
4 \text { Female }\end{array}$ & $\mathrm{w}$ & Mean 16 months & $\begin{array}{l}6 \text { right } \\
3 \text { left }\end{array}$ & $\begin{array}{l}\text { Surgical } \\
\text { exci- } \\
\text { sion }\end{array}$ & $\begin{array}{l}\text { Final follow-up total } \\
\text { strength recovery }\end{array}$ \\
\hline
\end{tabular}


Table 1 (continued)

\begin{tabular}{|c|c|c|c|c|c|c|c|c|c|}
\hline References & Cases & Zone $^{\mathrm{a}}$ & Age & Sex & $\begin{array}{l}\text { Symp- } \\
\text { toms }\end{array}$ & DSBS & Side & $\begin{array}{l}\text { Treat- } \\
\text { ment }\end{array}$ & Follow-up ${ }^{b}$ \\
\hline $\begin{array}{l}\text { 32. Jayaku- } \\
\text { mar et al. } \\
{[43]}\end{array}$ & 1 & $\begin{array}{l}1 \text { dumb- } \\
\text { bell } \\
\text { shaped/ } \\
\text { carpal } \\
\text { tunnel }\end{array}$ & 59 & Male & $\begin{array}{c}\text { w, par, } \\
\text { p, a }\end{array}$ & 48 months & Dominant & $\begin{array}{l}\text { Surgical } \\
\text { exci- } \\
\text { sion }\end{array}$ & 6 months \\
\hline $\begin{array}{l}\text { 33. Bingol } \\
\text { et al. [44] }\end{array}$ & 1 & 3 & 40 & Male & $\mathrm{s}, \mathrm{n}$ & 5 months & Left & $\begin{array}{l}\text { Surgical } \\
\text { exci- } \\
\text { sion }\end{array}$ & Clinical recovery (2) \\
\hline $\begin{array}{l}\text { 34. Gan and } \\
\text { Tan [45] }\end{array}$ & 1 total 13 & 1 & 51 & Female & $\mathrm{n}, \mathrm{w}$ & 8 months & Right & $\begin{array}{l}\text { Surgical } \\
\text { exci- } \\
\text { sion }\end{array}$ & 12 months \\
\hline
\end{tabular}

$w$ weakness, par paresthesia, $n$ numbness, $a$ atrophy, $s$ swelling, $p$ pain, DSBS Duration of Symptoms Before Surgery

${ }^{\mathrm{a}}$ Gross and Gelbermann et al. [51]

$\mathrm{b}$ (months) when it is not referred

Publisher's Note Springer Nature remains neutral with regard to jurisdictional claims in published maps and institutional affiliations. 